\title{
Growth Chart Percentile
}

National Cancer Institute

\section{Source}

National Cancer Institute. Growth Chart Percentile. NCI Thesaurus. Code C98260.

A commonly used clinical indicator to assess the size and growth pattern of an individual child. Percentiles indicate a rank of what percent of the reference population the individual would equal or exceed. 